REVISTA DE DERECHO UNED, NÚM. 26, 2020

\title{
POR QUÉ DISMINUIR LA PENA EN LOS DELITOS DE PREPARACIÓN
}

\author{
WHY TO REDUCE THE SENTENCE IN CRIMES OF \\ PREPARATION
}

ROBERTO CRUZ PALMERA

Resumen: En estas páginas se vuelve a criticar la inclusión de conductas de preparación en el Código Penal español, en concreto, esta contribución se centra en brindar algunos motivos por los cuales se estima necesaria la disminución de las penas actualmente previstas para los denominados "delitos de preparación". La tesis aquí mantenida se basa en la distinción entre dos etapas de la responsabilidad penal de toda conducta humana: la primera, la relevancia de los efectos o resultados de un delito; la segunda, la valoración de la intensidad de su preparación.

Palabras clave: Preparación, proporcionalidad, sanción, disminución.

Abstract: In these pages, the inclusion of preparatory actions in the Spanish Penal Code is criticized once more. Specifically, this contribution is centered on providing several motives for which it is judged necessary to reduce the currently defined sentences for the "crimes of preparation." The thesis maintained here is based on the distinction between two periods of time or basic moments of penal responsibility of all human behavior: the first, the relevance of the effects or results of a crime; the second, the valuation of the intensity of its preparation.

Key words: Preparation, proportionality, sanction, reduction.

Sumario: I. Planteo. II. ¿Por qué disminuir la pena en los delitos de preparación? III. El principio de proporcionalidad penal y su 
relación con la norma constitucional. IV. Efectos de la disminución penológica. V. Conclusión. VI. Bibliografía.

Recepción original: 7-1-2020

Aceptación original: 29-5-2020

\section{PLANTEO}

En estas páginas me propongo responder por qué es necesario disminuir las penas actualmente previstas para los "delitos de preparación" en el Código Penal español (CP). La actualidad del tema y lo excepcionalmente debatido de todas las cuestiones que le corresponden justifican continuar nuevamente el estudio de estos preceptos. Pues bien, no pretendo convertir este trabajo en una crítica sobre las decisiones legislativas que incluyen instrumentos de anticipación con formulaciones indeterminadas o de escasa ofensividad, tampoco entraré a cuestionarme la impunidad general o parcial para estos delitos. Sin embargo, debido a la complejidad de la materia, trataré de manera transversal algunos de esos aspectos. Me limitaré, esencialmente, en brindar algunas razones por las cuales considero necesario disminuir las penas actualmente previstas para los "delitos de preparación"1.

1 En este trabajo no brindaré una recopilación de todos los preceptos que se corresponden con la categoría de "delitos de preparación" en el CP; pero sí anotaré, mediante una sistemática propia, una muestra significativa de estas figuras. En primera línea, relacionados con la tenencia de objetos para delinquir: fabricación, introducción, posesión, o facilitación de programas informáticos destinados a la realización de una estafa (art. 248.2 b]); fabricación, importación, posesión con finalidad comercial de cualquier medio para facilitar la supresión no autorizada de cualquier dispositivo para desproteger obras literarias (art. 270.6); fabricación, importación, distribución o facilitación por vía electrónica de equipo o programa informático para hacer posible el acceso inteligible a un servicio de radiodifusión (art. 286.1); apoderamiento, trasporte, tráfico o tenencia de materiales nucleares sin la respectiva autorización (art. 345); fabricación, transporte, distribución, comercialización o tenencia de equipos, materiales, o sustancias para el cultivo, producción o tráfico de drogas (art. 371.1); tenencia, recepción u obtención de moneda falsa para su expedición o distribución (art. 386.2); tenencia de tarjetas de crédito o débito o cheques de viaje falsificados destinados al tráfico (art. 399 bis); elaboración, recepción, tenencia de útiles, materiales, instrumentos, sustancias, datos o programas informáticos destino a realizar falsedades (art. 400). En segunda línea, normas que sancionan desde la preparación una relación con la víctima, se sanciona a quien contacte con un menor de dieciséis años y le proponga concertar un encuentro con la finalidad de realizar alguno de los delitos descritos en los arts. 183 y 189 del CP (art. 183 ter. 1); se castiga a los fabricantes o a los comerciantes que, en sus ofertas o publicidades de productos, hagan alegaciones falsas o manifiesten inciertas sobre las características u objetos publicitados, de modo que puedan producir un perjuicio grave y manifiesto a 
La sanción prevista para estos delitos, en la legislación española, no depende del grado de afectación que con estos se "produzca" al bien jurídico ${ }^{2}$, pues el legislador sanciona, en no pocos casos, de la misma manera o de modo similar tanto la preparación delictiva como la realización perfecta del tipo doloso del respectivo delito fin ${ }^{3}$. Dicha previsión tampoco está relacionada con la clase de bien jurídico protegido, pues esta figura de anticipación se emplea para proteger distintos intereses jurídicos ${ }^{4}$. Como ejemplo podemos citar tipos penales que protegen la fe pública o el patrimonio económico, art. 400, delito de preparación para la comisión de falsedades 5 . Tam-

los consumidores (art. 282); se sanciona a quienes empleando violencia, amenaza o engaño, intenten alterar los precios que hubieren de resultar de la libre concurrencia de los productos, mercancías, títulos valores (art. 284). En tercera línea, tipos penales que incriminan la relación de acciones de terceras personas, actos de reforzamiento de la disposición para realizar delitos de desórdenes públicos sobre un grupo de personas o sobre un individuo determinado (art. 557.2), acciones de distribución o difusión pública, a través de cualquier medio, mensajes o consignas que inciten a la comisión de alguno de los delitos de alteración del orden público, o, de otro modo, aquellas que puedan reforzar la decisión de realizarlos (art. 559); conductas relacionadas con la financiación del terrorismo (art. 576); acciones de colaboración con actividades de grupos terroristas (art. 577). En cuarta línea, conductas de influencia que se consideran de tipo preparatorio, se castiga al particular que influya en un funcionario público aprovechándose de cualquier situación derivada de su relación personal con éste con la finalidad de conseguir una resolución que le pueda generar directa o indirectamente un beneficio económico para sí o para otras personas (art. 249), se sanciona al funcionario público o a la autoridad que influya en otro funcionario, aprovechándose del ejercicio de las facultades de su cargo, o de cualquier otra situación derivada de su relación personal (o jerárquica) con éste o con otro funcionario para conseguir una resolución que le pueda generar directa o indirectamente un beneficio económico para sí o para terceras personas (art. 428), se castiga a quien sedujere o allegare a tropa o cualquier clase de fuerza armada para cometer el delito de rebelión (art. 475); se prohíbe el acceso de manera habitual a uno o a varios servicios de comunicación abiertos al público cuyos contenidos resulten idóneos para la incorporación a grupos terrorista o capacitarse para la comisión de un delito de terrorismo (art. 575.2).

2 Mir Puig, S. Derecho penal. Parte general, 10. ${ }^{a}$ ed., Barcelona, Reppertor, 2015, página. 346.

3 Pueden servir como ejemplo este par de preceptos: art. 248.2 b), tenencia de instrumentos y programas destinados a la comisión de una estafa electrónica; art. 400, tenencia, posesión de instrumentos, programas o aparatos, específicamente destinados a la comisión de delitos de falsedades.

4 Luzón Peña, D.M., Lecciones de Derecho Penal. Parte General, 3. ${ }^{\text {a }}$ ed., Valencia, Tirant Lo Blanch, 2016, página. 168.

5 Muñoz Conde, F./García Arán, M., Derecho penal. Parte general, 9. a ed., Valencia, Tirant Lo Blanch, 2015, página 444; Silva SÁNchez, J.M., en Silva SánChez, J.M., (dir.)/Ragués I VaAllès (coodr.), Lecciones de Derecho penal, 5. a ed., Barcelona, Atelier, páginas, 356-361; Alonso De Escamilla, A./Mestre Delgado, E., en Lamarca Pérez, C., (coorda.), Delitos. La parte especial del Derecho penal, Madrid, Dikynson, 2015, páginas 707-712; OrTs Berenguer, E., en Vives AN-

(C) UNED. Revista de Derecho UNED, núm. 26, 2020 
bién, normas que protegen intereses irrecuperables como la vida humana y otros intereses, art. $575 .{ }^{1}$, delito de preparación para cometer actos de terrorismo ${ }^{6}$. De ese modo, vemos la potestad del legislador para establecer la pena que estime "oportuna" en este ámbito.

En el primer supuesto se contempla una sanción igual tanto para la preparación delictiva como para la realización perfecta del tipo base; para el segundo supuesto, la sanción es muy similar si la comparamos con la pena prevista para los actos preparatorios ${ }^{7}$.

Casi nadie discutiría que la sanción para la preparación delictiva debería ser siempre menor, al menos, a la establecida para la tentativa del respectivo tipo base, esto es, para el ilícito que el sujeto prepara $^{8}$, porque el contenido del injusto es parcial, y en algunos casos, difuso. En las legislaciones que contemplan la incriminación de "actos preparatorios punibles" como figuras de anticipación dependiente, resulta habitual que la pena sea inferior a la prevista para el correspondiente delito fin y, en general, suelen ser sanciones moderadas 9 . Así, es el caso del modelo español que de acuerdo con la in-

TÓN, T. (coord.), Derecho penal. Parte especial, 3. ${ }^{\text {a }}$ ed., Valencia, Tirant Lo Blanch, 1999, página 711; Queralt Jiménez, J., Derecho penal español. Parte especial, 6. ${ }^{a}$ ed., Barcelona, Altelier, 2010 página 596; Morillas Cueva, L. en Morillas Cueva, L., (coord.) Sistema de Derecho penal, 2. ${ }^{a}$ ed., Madrid, Dikinson, 2016, página 1089; Córdoba Roda, J. en Córdoba Roda, J./García ArÁN, M.(dirs.), Comentarios al Código penal, Madrid, Marcial Pons, 2011, página 1875; Lloria GarCía, P., en Boix ReIG, J. (dir.), Derecho penal. Parte especial, Vol. 3, Madrid, Iustel, 2012, página 450; AlCÁCER GUIRAO, R., "Tentativa consumación y anticipación de la protección penal: iter criminis y Derecho Penal económico" en Silva SÁnchez, J./ Miró Llinares, F. (dirs.) La teoría del delito en la práctica penal económica, Madrid, La Ley, 2013, páginas 558-559; Flores Prada, Criminalidad informática: Aspectos sustantivos y procesales, Valencia, 2012, páginas 234- 237; REYES AlvaRADo, Y., El delito de tentativa, Buenos Aires, Montevideo, BdF, 2016, página 280.

6 Campo Moreno J.C., Comentarios a la reforma del Código penal en materia de terrorismo: La L.O. 2/2015, Valencia, Tirant Lo Blanch, 2015, páginas 61-63;

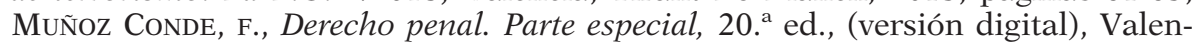
cia, Tirant Lo Blanch, 2015, páginas 767-769; JAÉn VAllejo, M./PERrino PéreZ, A. en La reforma penal de 2015. Análisis de las principales reformas introducidas en el Código Penal por las Leyes Orgánicas 1 y 2 de 2015, de 30 de marzo, Madrid, Dikinson, 2015, páginas 195-196; Olmedo Cardenete, M., en Morillas Cueva, L. (dir.), Sistema de Derecho penal. Parte Especial, 2. ${ }^{\text {a }}$ ed., Madrid, Dikinson, 2016, páginas 1436-1437; BARbER Burusco, S., «Del delito de "difusión” o "propaganda” terrorista a la desmesurada expansión de la punición de actos preparatorios", CPC 2015 núm. 16, páginas 64-65; SAnz Mulas, N., Política Criminal, Salamanca, Legis Juridica, 2016, páginas 278, 288.

7 Fuentes Osorio, F., La preparación delictiva, Granada, Comares, 2007, páginas, 100-101.

8 Fuentes Osorio, La preparación delictiva, Granada, Comares, páginas 36-40.

9 López Barja De Quiroga, J., Tratado de Derecho penal. Parte general, Cizur Menor (Navarra), Thomson Reuters Aranzadi, 2010, páginas 871-872. 
criminación de actos estrictamente preparatorios, en los arts. 17 y 18 del $\mathrm{CP}$, se prevé sancionar únicamente aquellos expresamente definidos con el título de "actos preparatorios punibles", que suelen caracterizarse por llevar consigo penas inferiores ${ }^{10}$, entre los que se encuentran el homicidio, el asesinato, el delito de rebelión, y otros ${ }^{11}$, siempre con sanciones menores respecto a la realización perfecta del delito base ${ }^{12}$. Sin embargo, la decisión de fijar sanciones desproporcionadas para los "delitos de preparación" en CP sigue vigente a pesar de contar con los ya conocidos "actos preparatorios punibles".

En algunas reformas que afectaron al CP no solo se incluyeron más "delitos de preparación"13, sino que, conjuntamente, para algunos supuestos se ampliaron las conductas tipificadas mediante la inclusión de verbos típicos ${ }^{14}$. De manera que se trata de una figura de anticipación que el legislador utiliza con más frecuencia ${ }^{15}$. Con todo,

10 CAmpo MoReno, J.C., Los actos preparatorios punibles, Valencia, 2000, páginas 20-31.

11 Barber Burusco, S., Los actos preparatorios del delito, Granada, Comares, 2004, páginas 129-155.

12 Cerezo Mir, J., Derecho penal. Parte general, Buenos Aires, Montevideo, BdF, 2008, páginas 900-906; MIR PUIG, DP. PG, 10. ${ }^{\text {a }}$ ed., 2015, páginas 350-354; Muñoz Conde, F./García ArÁn, M., DP. PG, 9. ${ }^{a}$ ed., 2015, páginas 479-480.

13 Pongo por caso, mediante la Ley Orgánica (en adelante, L.O.) 1/2015, se incluyeron nuevas conductas delictivas en el CP, pero también se reformaron algunas normas que ya existían respecto a los "delitos de preparación". Además, mediante esa reforma se incrementa la edad del consentimiento sexual a dieciséis años, modificación que afecta a un precepto que ya existía con anterioridad. Nos referimos al art. 183 ter del CP, actualización del anterior art. 183 bis. En similar dirección, esa L.O. introduce dos “delitos de preparación”, arts. 557.2 y 559. Así pues, aparece también el precepto de difusión de mensajes que faciliten la comisión de algún delito de desórdenes públicos. Finalmente, en la exposición de motivos de la L.O. 2/2015, de 30 de marzo, se evidencia tanto la inclusión como la modificación de delitos de preparación, art. 575. El legislador expone la necesidad de reformar la Ley Penal en esa materia. Se trata del denominado "pacto antiterrorista", en donde los Estados se comprometen a reforzar su legislación para atacar ese fenómeno.

14 Ramos Vázouez, J.A, en Quintero Olivares, G., (dir.), Comentario a la reforma penal de 2015, Cizur Menor (Navarra), Thomson Reuters Aranzadi, 2015 páginas 438-446.

15 Sobre este punto resulta interesante el análisis de la Reforma trazado por Muñoz Conde, F./García ArÁN, M., DP. PG, 9. ${ }^{a}$ ed., 2015, páginas 444-447, 480. De cara a los aspectos dogmáticos nos recuerda la modificación para los actos preparatorios punibles, puntualmente en la proposición para delinquir, pues en el precepto contenido en el art. 17.2 se ha reemplazado el término "ejecutarlo" por la expresión "a participar en él". Dicha modificación extiende, como se sabe, esta figura de anticipación. Ahora bien, en lo que respecta a la configuración y redacción de nuevos tipos penales que amplían el ámbito de prohibición, incriminando fases previas a la tentativa, esta doctrina advierte la inclusión y modificación de actos preparatorios elevados a la categoría de delito autónomo en el CP

(C) UNED. Revista de Derecho UNED, núm. 26, 2020 
puede afirmarse que a pesar de la existencia de los "actos preparatorios punibles", nos resulta sorprendente no solo que existan adicionalmente "delitos de preparación", sino además, que estos últimos se castiguen con penas desproporcionadas ${ }^{16}$. Este modo de proceder del legislador, no puede ser nunca asumido como algo normal, por esto, estimo conveniente cuestionarnos por qué es necesario disminuir la pena en los "delitos de preparación" ¿Cuál es la necesaria razón de sancionar estas figuras de forma moderada?

A primera vista, la razón de sancionar los "delitos de preparación" con penas elevadas podría parecer una cuestión próxima a la Política legislativa y, por lo tanto, distante a cuestiones dogmáticas. De ser así, entenderíamos el asunto simplemente como una distribución de niveles preventivos para conductas complejas ${ }^{17}$, ya que varios de los denominados "delitos de preparación" incriminan supuestos relacionados con instrumentos $\mathrm{u}$ objetos tecnológicos ${ }^{18} \mathrm{pu}-$ diendo incriminar conductas neutras ${ }^{19}$. El modo de proceder del legislador respecto a los "delitos de preparación" no me parece acertado. Y sostengo que no lo es, puesto que engloba una visión de Política legislativa en donde destaca un ámbito de desproporción ${ }^{20} \mathrm{y}$, por tanto, de inseguridad jurídica, lo que precisa seriedad y raciona-

("delitos de preparación"), especialmente para acciones terroristas y de desórdenes públicos, pero también para otros campos.

16 Alonso Rimo, A. ¿Impunidad general de los actos preparatorios? La expansión de los delitos de preparación, InDret 4/2017, páginas 61-64.

17 FeIJoo SÁnchez, B., Retribución y prevención general. Un estudio sobre la teoría de la pena y las funciones del Derecho Penal, Montevideo, Buenos Aires, Bdf, 2007, páginas 773-784.

18 Entre otros, arts. 217.6, 248.2 b, 286.1, 345, 371.1, 386.2, 399 bis, 400, 563.

19 Manzanares Samaniego, J.L., Comentarios al Código Penal, Madrid, La Ley, 2016, , página 1330; Colmenero Menéndez De Luarca, M., en Conde-PumPIDO Ferreiro, C. (dir), Código penal comentado, 3. ${ }^{a}$ ed., Tomo 1, 2012, página 1015; Gómez Martín, V., en Corcoy Bidasolo, M./Mir Puig, S.(dirs.), Comentarios al Código penal, Valencia, Tirant lo Blanch, 2015, página 961; CRUZ DE PABLO, J.A., Derecho penal y nuevas tecnologías. Aspectos sustantivos, Madrid, Grupo difusión, 2006, página 46; Serrano Gómez, A./Serrano Maíllo, en Serrano GóMEz, A., et.al, Curso de Derecho Penal, 4. ${ }^{a}$ ed., Madrid, Dikynson, 2017, página 659; Miró Llinares, F., «La respuesta penal al ciberfraude. Especial atención a la responsabilidad de los muleros del phishing», en $R E C P C$, núm. 15 (2013), página 24; Pastor Muñoz, N. en Silva Sánchez, J., (dir.) y Pastor Muñoz, N. (coord.), El nuevo Código penal. Comentarios a la Reforma, Madrid, La Ley, 2012, páginas 338-339. A todo esto, la expresión doble uso aparece repetidamente en la Ley de represión del Contrabando, L.O. 12/1995, de 12 de diciembre. Por eso, es muy probable que se haya tomado de esa Ley.

20 Robles Planas, R. "La tiranía de la proporcionalidad», en García Cavero, P./Chinguela Rivera, A. (coodrs.), Derecho Penal y persona. Libro Homenaje al Prof. Dr. H.C. Mult. Jesús María Silva Sánchez, Lima, Ideas, 2019, páginas 130-131. 
lidad si se pretende que la medida sea valorada como Política ${ }^{21}$. Por otra parte, las sanciones desproporcionadas en los "delitos de preparación" acarrean consecuencias prácticas, piénsese en la indiscutible oposición entre los actos de escrita preparación frente a los de ejecución, con los efectos jurídicos que producen ${ }^{22}$. No es lo mismo preparar un delito que realizarlo ${ }^{23}$; sin embargo, las penas previstas en los "delitos de preparación" abandonan esta lógica, porque, como se adelantó, en algunos casos la sanción es próxima a la del tipo base (por ejemplo, arts. 183 ter, 270.6, 282, 284, 386.2). Y en otros, la pena de la preparación es igual la prevista para la realización perfecta delito fin (por ejemplo, arts. 248.2 b], 399 bis 2, 371, 400, $557.2)^{24}$. En ese sentido, entiendo que la determinación del injusto

21 Mir Puig, S., DP. PG, 9. a ed., Barcelona, 2011, página 128: "Dos aspectos o exigencias hay que distinguir en el principio de proporcionalidad de las penas. Por una parte, la necesidad misma de que la pena sea proporcionada al delito. Por otra parte, la exigencia de que la medida de la proporcionalidad se establezca en base a la importancia social del hecho (a su "nocividad social"). La necesidad misma de la proporción se funda ya en la conveniencia de una prevención general no sólo intimidatoria, sino capaz de afirmar positivamente la vigencia de las normas en la conciencia colectiva (prevención general positiva) [...]. Esta afirmación de las normas aconseja apoyar con mayor pena las más importantes que las que lo son menos, con objeto de evitar que aquéllas se devalúen. Pero un Estado democrático debe exigir, además, que la importancia de las normas apoyadas por penas proporcionadas no se determine a espaldas de la trascendencia social efectiva de dichas normas. Se sigue de ello que un Derecho penal democrático debe ajustar la gravedad de las penas a la trascendencia que para la sociedad tienen los hechos a que se asignan, según el grado de la "nocividad social" del ataque al bien jurídico".

22 Paredes Castañón, J., La justificación de las leyes penales, Valencia, Tirant Lo Blanch, 2013, página 319: "Cuando [...] hablamos de proporcionalidad entre infracción y sanción, no sólo comparamos -aunque también- valor del bien jurídico y afectación a derecho fundamentales, sino, más en general, aquel valor del bien jurídico con la aflicitividad de la sanción -que incluye la afectación de la misma a derecho fundamentales, pero no sólo. La proporcionalidad entre infracción y sanción no es más que una forma de intentar medir la justicia de la acción. Es decir, posee siempre significación moral: una sanción desproporcionada, es siempre una sanción injusta, moralmente injustificable".

${ }_{23}$ Paredes Castañón, La justificación de las leyes penales, página 248. Al abordar un sugestivo análisis de la ponderación de la desproporción, defiende la necesidad de conectar la prohibición jurídica con la protección de los bienes jurídicos, afirmando que "no es lo mismo una prohibición de acciones abstractamente peligrosas que de acciones lesivas, o de acciones muy lesivas que de acciones menos lesivas".

${ }^{24}$ Podrían citarse más de estos ejemplos, al respecto, véase, CRUZ PALMERA, R, Delitos instrumentales: Aspectos de Politica legislativa, Buenos Aires, Montevideo, $\mathrm{BdF}$, en presan.

Hemos visto que con los "delitos de preparación” el legislador puede extender la protección del bien jurídico hasta el punto que estime. Por ejemplo, castigando la posesión de instrumentos que pueden ser útiles para cometer un determinado delito. Empero, creo que es correcto que el legislador, también en este punto, fije

(C) UNED. Revista de Derecho UNED, núm. 26, 2020 
penal resulte incompatible con la idea de injusto en la preparación delictiva que caracteriza a los "delitos de preparación"25. Creo que en la medida en que seamos conscientes de la necesaria disminución de las penas para estas figuras de anticipación, tendremos criterios para exigir al legislador una propuesta alternativa relacionada en la forma en que deban castigarse estos actos.

Para continuar destacando la importancia de esta materia, me gustaría repasar algunas características de este fenómeno que he apreciado en la legislación penal, y que a mi juicio encubren un modo equivocado de tratar la preparación delictiva y su gravedad. En primer lugar, considerar "delitos de preparación" acciones que llevan consigo la búsqueda de instrumentos o algún otro aspecto creativo doloso con condiciones competentes para la perpetración de una infracción penal ${ }^{26}$. Como se sabe, cuando nos referimos a los "delitos de preparación", estamos ante una incriminación previa a la fase de la tentativa que no requiere necesariamente la implicación de varios sujetos para materializar un proyecto criminal. Los "delitos de preparación" sancionan, entre otras conductas, la tenencia, la posesión, y la facilitación de instrumentos para delinquir (arts. 248.2 b], tenencia, fabricación o facilitación de objeto o instrumentos para cometer una defraudación informática; 270.6, tenencia, fabricación o facilitación de aparatos para lesionar la propiedad intelectual; 371.1, posesión, fabricación, facilitación de instrumentos u objetos para cometer delitos contra la salud pública, por ejemplo). Además, se consideran delictivas acciones orientadas a la comisión

algunos límites a su potestad, aunque sean actos dolosos que se encuentren en etapa de preparación. Fenoménicamente no es lo mismo la capacidad de lesionar que causar una lesión... Esta postura, que surge del análisis de las sanciones previstas para los "delitos de preparación", puede imponerse ante la decisión de equiparar, en términos penológicos, la preparación con la realización perfecta del tipo base. Dicha equivalencia, contradice a todas luces tanto le principio de legalidad como el de proporcionalidad penal, principios que impiden equiparar la misma sanción ante resultados cuantitativamente diferentes.

25 Frister, H., Strafrecht, Allgemeiner Teil, 5. ${ }^{a}$ ed., Múnich, Beck C. H, n. m. 32. Sobre este particular, sostiene que la facultad del legislador tiene un límite, este es, sancionar, únicamente, aquellas acciones que no afecten de ninguna manera a la posibilidad de desarrollo de los ciudadanos. Por lo tanto, los "delitos de preparación" no pueden ser sancionados de forma desequilibrada.

También de este parecer, Muñoz Conde, F. /García Arán, M., DP. PG, 9. a ed., 2015, página 322. Esta doctrina, al referirse a la noción de injusto penal, afirma que: "La esencia de la antijuricidad es la ofensa a un bien jurídico protegido por la norma que se infringe con la realización de la acción. En la medida en que no se dé esa ofensa al bien jurídico no podrá hablarse de antijuricidad, por más que aparente o formalmente exista una contradicción entre la norma y la acción".

26 Al respecto, véase, Greco, L, "Dolo sin voluntad", RNFP, Vol. 13, No. 88, paginas $16-19$. 
de otro delito sin que se intenten ${ }^{27}$ (art. 570.2, adoctrinamiento pasivo para cometer un acto de terrorismo, por ejemplo). De los ejemplos descritos -que podrían fácilmente incrementarse- deriva en mi opinión que el modo de proceder del legislador resulta llamativo. En segundo lugar, también se consideran "delitos de preparación" las acciones o posibilidades que puede adquirir un sujeto para invadir el ámbito organizativo de otro; con esto, en mi opinión, se pretende evitar a cualquier precio la posibilidad de una lesión (art. 400). Conjuntamente, en tercer lugar, como se adelantó, los "delitos de preparación" representan un mecanismo de protección para distintos bienes jurídicos ${ }^{28}$, esto demuestra que no son una figura de corte excepcional. Así pues, en el CP contamos con preceptos que sancionan actos preparatorios para realizar lesiones directas a la persona: se habla de una afectación a un individuo; por esto, podemos afirmar que dichos preceptos se constituyen como una herramienta de anticipación para bienes jurídicos individuales, sirva de ejemplo: delito de propuesta sexual telemática ${ }^{29}$, art. 183 ter. También se castiga la preparación para lesionar algunos bienes jurídicos referidos a la colectividad en el sentido más amplio que pueda pensarse, por ejemplo: delito de seducción a tropa o cualquier fuerza armada para cometer delito de rebelión ${ }^{30}$, art. 475. Así las cosas, esta técnica también se presta para proteger bienes jurídicos de carácter colectivo. En ese orden de asuntos, puede llegar a pensarse que el legislador entiende la preparación delictiva como una figura de distribución de niveles preventivos que dependen de las nuevas o complejas circuns-

27 Cano Paños, M. en Morillas Cueva, L. (dir.), Estudios sobre el Código penal reformado. Leyes Orgánicas 1/2015 y 2/2015, Madrid, Dikinson, 2015, páginas 905-951; JAÉN VALLeJo/PERrino PÉRez, La reforma penal de 2015, páginas 188-197; Campo Moreno, J.C., Comentarios a la reforma del Código penal, página 61; MuÑoz CONDE, F., DP. PE, 20. a ed., (versión digital), 2015, página 768.

28 Sirvan de ejemplo: art. 248.2 b], patrimonio económico; art. 282 patrimonio económico, art. 286.1, patrimonio económico, art. 345, seguridad colectiva, art. 386.2, patrimonio económico, 399 bis, fe pública, 428, Administración de Justicia, art. 475, Seguridad del Estado; art. 563, Seguridad del Estado; art. 557.2, Orden Público; art. 559, Orden Público; art. 576, Orden Público; art. 577, Orden Público. De manera resumida, puede decirse que estos preceptos representan un proyecto de reforzamiento para la protección de los siguientes bienes jurídicos. La vida, la salud pública, la fe pública, la paz pública, el buen funcionamiento de la Administración de Justicia, el orden Constitucional del Estado, la libre regulación del mercado en provecho de los intereses de los consumidores. Además, apreciamos un reforzamiento del patrimonio económico, la propiedad intelectual y la indemnidad sexual de los menores.

29 Ramos Vázouez, J., A., "Ciberacoso", en Quintero Olivares, G. (dir.), página 439.

30 Serrano Gómez, A./Serrano Maíllo, A. en Serrano Gómez, a., et. al., Curso

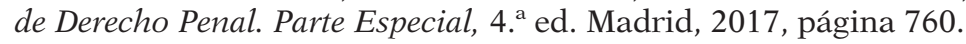

(c) UNED. Revista de Derecho UNED, núm. 26, 2020 
tancias que amenazan o pueden amenazar a la sociedad, pero, como señalamos en su momento, no se asume mediante criterios relacionados como la importancia del bien jurídico o la peligrosidad intrínseca que caracteriza a la conducta.

Estos modos de proceder nos muestran que los "delitos de preparación" se han apartado de los criterios de sanción, normalmente empleados, que deberían caracterizar a la preparación delictiva -lo cual no solo es algo negativo, sino equivocado, desde mi punto de vista-, pero además evidencian que la normativización de estas conductas se realiza sin expresar razones para cada caso que avalen la incriminación de un acto preparatorio a la categoría de delito ${ }^{31}$. Esto también me parece errado en el modo de atender la preparación delictiva por parte del legislador: es sorprendente que se hayan asumido parámetros de estricta prevención para castigar un conjunto significativo de actos preparatorios autónomos en el $\mathrm{CP}^{32}$, pasando por alto que únicamente debe acudirse al castigo de la preparación cuando se trate de conductas graves, pero aplicando sanciones moderadas $^{33}$. También por estas razones se torna necesario cuestionarnos el porqué de la necesidad de disminuir las penas en los "delitos de preparación".

En adelante, mi exposición plantea el motivo o los motivos para dicha disminución, para preguntarnos a continuación si dicha salida resulta compatible con el principio de proporcionalidad penal y su relación con la norma constitucional. Y, por último, la conclusión.

31 Sobre la necesidad de justificar la incriminación de conductas, PAREDES CASTAÑón, La justificación de las leyes penales, páginas 175-179.

32 Robles Planas, R., "Introducción a la edición española. Dogmática de los límites al Derecho penal», en Hirsch/SEelman/WoHLERs, Límites al Derecho penal. Principios operativos en la fundamentación del castigo, Barcelona, Atelier, 2012, página 20. A mi modo de ver, y siguiendo el planteamiento trazado por el autor, entiendo que la necesidad de incriminar conductas con fines preventivos en nuestra sociedad no debería ser un óbice para tomar decisiones irracionales, es decir, aquellas que contradigan abiertamente los límites que deben respetarse en materia de intervención penal.

33 FERrini, C., Derecho Penal romano, Madrid, Marcial Pons, 2017, páginas 101-104. Desde el antiguo Derecho romano se mantuvo la necesidad de omitir el castigo de los actos que no lleguen a la consumación, exceptuando las conductas encaminadas a usurpar el poder, al cambio drástico, por no decir violento, del poder, o a la traición de la patria. Como puede verse, se trata de acciones excepcionales. 


\section{II. ¿POR QUÉ DISMINUIR LA PENA EN LOS DELITOS DE PREPARACIÓN?}

La preparación delictiva y la ejecución del delito no solamente son supuestos distintos, sino distantes en términos temporales, pues en todo delito (doloso) el autor reserva un espacio temporal para la preparación que exige la materialización del proyecto delictivo ${ }^{34}$. Al encontrarnos ante un momento intermedio, entre la fase interna y el período de la ejecución del delito, debería mediar entre la preparación del delito y la ejecución una distinción valorativa en función de la percepción de la gravedad de las conductas, de modo que la preparación delictiva que caracteriza a los "delitos de preparación" deban llevar aparejadas sanciones acordes al grado de peligrosidad, aunque en la preparación y la ejecución compartan un mismo querer. La sanción de los "delitos de preparación" debe ser menor que la realización perfecta del tipo base, porque su gravedad es inferior, pues como ya hemos adelantado, no es lo mismo la capacidad de lesionar o la disposición de dañar a otro que el daño causado ${ }^{35}$. Este modo de entender la preparación delictiva puede estar motivado por razones históricas, psicológicas, legislativas y sociológicas. Veamos. Por razones históricas, la sanción de los actos de preparación es, por lo general, impune ${ }^{36}$, al no representar ni peligro ni lesión para los intereses jurídicos protegidos por el ordenamiento jurídico ${ }^{37}$. Hasta donde alcanzo, esta razón se fundamenta en que el Derecho penal marca una distinción entre Derecho y Moral, restringiendo el castigo tanto para los pensamientos como para las esferas de libertad personal de cada sujeto y, en estas últimas, encajarían en cierto modo los actos de preparación ${ }^{38}$. De manera que estas conductas tendrían que castigarse, únicamente, cuando se determinen situaciones excepcionales $^{39}$, esto es, cuando representen una verdadera amenaza

34 Espinosa, P., "Modelos de conducta y toma de decisiones morales", en CLEMente, M.,/Espinosa, P., (coords.), La mente criminal, Madrid, Dikynson, 2001, páginas 180-186.

35 Lesch, H., El concepto de delito, (trad. Germignani), Madrid, Marcial Pons, 2016, páginas 209-2012.

36 Roxin, C. "El fundamento del castigo de la tentativa idónea e inidónea" (trad. Queralt), en Silva SÁNchez, et. al., (coords.), Estudios de Derecho Penal. Homenaje al profesor Santiago MIR PUIG, Buenos Aires, Montevideo, Bdf, 2017, página 848.

37 Fiandaca, G./Musco, E., Diritto penale. Parte generale, 4. a ed., Bolonia, Zanichelli, 2001, página 3 .

38 JakoBS, G. en Estudios de Derecho penal, (trads. Peñaranda Ramos/Suárez González/Cancio Meliá), Madrid, Civitas, 1997, página 295.

39 JaÉn Vallejo, M., Los principios superiores del Derecho penal, Madrid, Dikyson, 1999, página 65. Si no lo mal interpretito, señala que el castigo de los

(c) UNED. Revista de Derecho UNED, núm. 26, 2020 
para la estabilidad de determinados bienes jurídicos ${ }^{40}$. Sin embargo, no cabe pasar por alto que la valoración de la preparación delictiva y de la ejecución del tipo habría traído consigo la asociación de consecuencias punitivas también graduales: impunidad o inferior pena de la preparación frente a la de los supuestos de realización perfecta del tipo fin. También podemos acudir a razones de carácter psicológico, fundadas en la percepción de que en casos de perfecta realización del tipo base el sujeto materializa la conducta o, al menos, puede quedar en tentativa. A diferencia de lo que sucede en la preparación delictiva, el sujeto dispone aún de un tiempo, quizá indeterminado, para llevar a cabo su plan, en todo caso, puede desistir, puede fracasar, puede replantear la preparación; también podrá postergar la ejecución, cambiar de planes...; pero sigue permaneciendo en un "estado de preparación", y eso implica no solo un distanciamiento de la producción del resultado, sino una ausencia de lesión al bien jurídico protegido. Además, por razones legislativas, la previsión de la responsabilidad por actos de preparación se entiende como excepcional respecto a la realización perfecta del tipo base ${ }^{41}$, de manera que acaban dependiendo conceptualmente de estos (del tipo base), lo cual abonaría una menor sanción, y debería plantearse dicho criterio con carácter general. Y, también, por razones sociológicas, pues la realización de los actos de preparación no representan desestabilización al orden social, o sea, son conductas que no afectan a nadie, pues al suponer un momento intermedio entre la fase interna ("pensamientos") y la ejecutiva ("resolución manifiesta de la voluntad"), están más cercanos al pensamiento que a la resolución manifiesta de la voluntad, al menos, por dos motivos. El primero, debido al alto grado de indeterminación o ambigüedad que caracteriza a la preparación delictiva ${ }^{42}$; el segundo, porque estos actos no interfieren en la libertad del desarrollo de nadie y, conjuntamente, no alcanzan, to-

actos preparatorios solo debería admitirse para algunos casos, centrando su explicación a supuestos límites como aquellos que suponen la imposibilidad de devolver las cosas a su estado anterior o ante la lesión de bienes jurídicos de primer nivel.

40 Rodríguez Devesa, J., Derecho penal español. Parte especial, 14. ${ }^{\text {a }}$ ed., Madrid, Dikynson, 1991, página 690.

41 Muñoz Conde, F./García Arán, M., DP. PG, 9. a ed., 2015, páginas 440, 444. Así, siguiendo el planteamiento de esta doctrina, para el legislador penal, el punto de referencia es el delito consumado, pues únicamente por motivos excepcionales decide, como manifestación de su potestad, incriminar acciones preparatorias que no representan certeza de lesión. Sin embargo, esa potestad no se agota con los "delitos de preparación", sino que puede acudir a otras figuras de adelantamiento, por ejemplo: delitos de tentativa, delitos de peligro abstracto, entre otras.

42 Cerezo Mir, J., DP. PG., 2008, página 909. 
davía, a perturbar la convivencia de los ciudadanos ${ }^{43}$. Como se mencionó, en no pocas circunstancias, algunos instrumentos que sirven para delinquir pueden encajar perfectamente en la realización de un acto lícito, por eso decimos que en la vida ordinaria se pueden realizar conductas lícitas con apariencia de ilicitud ${ }^{44}$.

$\mathrm{Al}$ revisar la Parte Especial del CP, vemos que estas razones parecen escasas. Al parecer, actualmente, el legislador español se encuentra "obligado" a sancionar de forma anticipada las acciones que puedan llegar a lesionar determinados bienes jurídicos. No obstante, estos modos de proceder ponen de manifiesto -tanto hoy como ayer- que el tratamiento de la preparación delictiva que caracteriza a los "delitos de preparación" manifiestan la arbitrariedad del legislativo. En todo caso, por las razones expuestas en este trabajo, resultaría conveniente la previsión de penas moderadas. En ese orden, creo que podría plantearse la posibilidad de optar por la pena de multa para estas modalidades "delictivas", pero nunca acudir a una sanción igual o muy similar a la prevista para la realización perfecta del tipo base (como ocurre en varios de los casos que hemos comentado en esta investigación).

Desde mi punto de vista, socialmente cada delito produce con un resultado, estoy pensando en el nivel de nocividad que deja -en mayor o menor medida- a todos los miembros de una comunidad, no me refiero a la impronta que el injusto produce en la víctima y a los sujetos cercanos a esta, sino al resto del colectivo (sensación de inseguridad con el delito de robo, estafa informática, por ejemplo). El legislador, al elevar actos de preparación a la categoría de delito amenaza con penas desproporcionadas, pero estas no pueden ser tenidas como admisibles.

En un Estado social y democrático de derecho, resulta difícil encontrar argumentos que sostengan el tratamiento penológico para los "delitos de preparación" actualmente previsto en el CP. Estas figuras, en su faceta de instrumento de anticipación penal, se fundamentan mediante criterios eminentemente preventivos ${ }^{45}$. Esto puede ser acertado solo si se reserva dicho instrumento para supuestos excepcionales y compatibles con la idea de la proporcionalidad penal en sentido amplio, esto es, para bienes jurídicos de primer nivel (intereses irrecuperables) y ante conductas con un margen objetivo de

43 Roxin, C./ Greco, L., Strafrecht, Allgemeiner Teil, Tomo I, 5. ${ }^{a}$ ed., Múnich, C.H. Beck, 2020, § 2 núm. 7.

44 Comparte esta idea, Naucke, W., Strafrecht. Eine Einführung, 8. a ed., Múnich, L.V.G, 1998, páginas 73-74.

45 FeIJOo SÁNCHEZ, B., Retribución y prevención general, páginas 515-519. 
gravedad. Piénsese, por ejemplo, en la tenencia de armas nucleares o de destrucción masiva.

\section{EL PRINCIPIO DE PROPORCIONALIDAD PENAL Y SU RELACIÓN CON LA NORMA CONSTITUCIONAL}

El tema de la disminución de la pena en los "delitos de preparación" engloba un asunto legislativo que exige razonabilidad, es decir, que transite por motivos plausibles, y, para esto, tales razones deben ser a la vez comprensibles. Lo ideal, a mi juicio, exige apartar estas decisiones de una potestad arbitraria o soberana, para acercarnos a medidas que se produzcan mediante criterios compatibles con los postulados de un Estado social y democrático de derecho ${ }^{46}$. Esto no es ajeno con las necesidades preventivas para la solución de problemas que afronta una determinada sociedad, con independencia de la clase de bienes jurídicos que requieran mayor protección.

En un Estado social y democrático de Derecho, en virtud del principio de proporcionalidad penal, las sanciones aplicadas deben guardar relación con el grado de afectación o la puesta en peligro que las conductas generan a los bienes jurídicos ${ }^{47}$. En ese sentido, el principio de proporcionalidad opera como mandato regulador ${ }^{48}$. Dicho en otras palabras, la aplicación de la pena deberá ser proporcional al grado de afectación de los bienes jurídicos, así como al nivel de ejecución alcanzado y, a su vez, debe ser proporcional respecto a las circunstancias personales del culpable. La intervención penal, esto es, la tipificación de la conducta, la imposición de la pena, así como su posterior ejecución; restringe derechos que afectan la dignidad de la persona. Por tal motivo, la proporcionalidad penal nos invita a establecer límites a esa arbitrariedad del legislativo ${ }^{49}$. La observancia del principio de proporcionalidad demanda del mismo modo que los "delitos de preparación" protejan bienes jurídicos de-

46 Comparte esta idea, Mir Puig, S., Estado, pena y delito, Montevideo, Buenos Aires, BdF, 2006, páginas 95-97.

47 Comparte esta idea, Mir PUIG, Estado, pena y delito, 2006, páginas 339-341.

48 Pedraz Penalva/Ortega Benito, «El principio de proporcionalidad y su configuración en la jurisprudencia del Tribunal Constitucional y literatura especializada alemana», DPJ núm. 17 (1990), páginas 69-79; RodRíguez De SANTIAGo, J. M., La ponderación de bienes e intereses en el Derecho administrativo, Madrid, Estudios Jurídicos, 2000, páginas 105-110; Zugaldía EsPINAR, M., Fundamentos de Derecho penal, 3. a ed., Valencia, Tirant Lo Blanch, 1993, páginas 263-266.

49 Véase también, Aguado Correa, T., El principio de proporcionalidad en Derecho penal, Madrid, EDR, 1999, páginas 120-128; MIR PUIG, S., DP. PG, 10. ${ }^{\text {a ed., }}$ 2015, páginas 138-139. 
terminados y no intereses jurídicos abstractos; conjuntamente, que estos sean realmente relevantes para la sociedad. En similar dirección, y por obvio que parezca, se requiere que sean susceptibles de un ataque y que puedan ser lesionados mediante una conducta realizada por el sujeto activo ${ }^{50}$ (no ejecutadas por otro) y sancionarse guardando un equilibrio en la asignación de la pena (grado de realización logrado y puesta en peligro). No obstante, en todos los preceptos que hemos recogido la pena es desproporcionada, puesto que señala una consecuencia jurídica que no se corresponde con la gravedad de la conducta incriminada, abandonando los lineamientos que nos marca el principio de proporcionalidad.

El principio de proporcionalidad penal encuentra su respaldo en varias constituciones, concretamente en España, el Tribunal Constitucional reconoció el carácter constitucional de este postulado STC 62/1982, de 15 de octubre- mediante los criterios de equidad, libertad y dignidad humana. Este postulado apela a la idea general de justicia ${ }^{51}$, por esto, las sanciones penales deben ser siempre idóneas para enlazarse con este mandato constitucional, pero también necesarias, porque de estas se requiere que las conductas incriminadas merezcan ser castigadas por vía penal; de esta manera, el principio de proporcionalidad penal requiere que el castigo de las conductas produzcan más beneficios para la sociedad en comparación con los inconvenientes que se producen al limitar derechos (pena privativa de libertad, privación para la realización de determinado cargo u oficio, prohibición de tenencia de objetos...). En ese orden, el principio de proporcionalidad también debería evitar la tipificación de conductas con penas desproporcionadas, sugiriendo elementos para su aplicación ${ }^{52}$.

La historia, al menos en el caso español, ha demostrado que la Constitución no se presenta como la única solución para determinar qué derechos han de alcanzar el estatus de bien jurídico. Esto

50 En sentido análogo, ANGioni, F., Concetto e funzioni del concetto di bene giuridico, Milán, Giuffrè, 1983, páginas 215-218.

51 Compárese con, Angioni, F., Concetto e funzioni del concetto di bene giuridico, Milán, 1983, páginas 215-218; MuÑoz Conde, F. /García ARÁN, M., DP. PG, 9. ${ }^{\text {a }}$ ed., Valencia, 2015, página 94.

52 De este parecer, Muñoz Conde, F. /García Arán, M., DP. PG, 9. a ed., Valencia, 2015, página 95: "La gravedad de la pena depende, además, de la forma de ataque al bien jurídico. Así, por ejemplo, un ataque doloso a la vida es mucho más severamente castigado (por ej., como asesinato), que uno o varios ataques imprudentes al mismo bien jurídico (por ej., diez homicidios por imprudencia grave a consecuencia de un accidente de tráfico). La diferencia no se hace en estos casos cuantitativa, sino cualitativa, es decir, en función del desvalor ético-social del comportamiento realizado". 
parece lógico, aunque en la parte dogmática de dicho texto se contengan valoraciones respecto a intereses reconocidos y protegidos en el CP, casi todos asumimos que no es esa precisamente la función de la Constitución. Aunque se afirme que detrás de un bien jurídico -"siempre" o "casi siempre"- se "esconde" un derecho constitucional, este texto no nos proporciona criterios para determinar ante qué clase de ataques han de protegerse esos intereses en el ámbito penal y qué clase de sanción debemos aplicar. No obstante, entiendo que no pueden alcanzar el estatus de bien jurídico penal los intereses que de alguna u otra forma no se consagren en la Constitución. Si bien ese texto, como mencionamos, no nos muestra de qué manera deben castigarse las conductas (clases de penal) o cuándo la protección debe ser por vía penal (clases de agresiones), el estudio sistemático de los principios constitucionales conjugando la idea de que el Derecho Penal deba ajustarse a la Constitución, nos permite decir que nuestro Derecho Penal tiene por finalidad la protección de bienes jurídicos y que debemos acudir a esta herramienta ante la lesión o puesta en peligro; pero también que las sanciones aplicadas deben ajustarse a los principios constitucionales (criterios de libertad, dignidad humana, justicia...). En ese orden de asuntos, el principio de proporcionalidad penal no se escapa de la interpretación sistemática de la Constitución. Como hemos mostrado, las sanciones, independientemente de la clase de delitos que introduzca el legislador penal, deben ajustarse a la gravedad de la lesión o a la proximidad del daño que se puede causar mediante la puesta en peligro; de lo contrario, las medidas no podrían ser reconocidas como justas. Dicho esto, si las sanciones son desproporcionales, estas tendrán que ser valoradas como ilegítimas $^{53}$.

\section{EFECTOS DE LA DISMINUCIÓN PENOLÓGICA}

Llegados a este punto, pasamos a apuntar algunos de los efectos que consideramos más relevantes de cara a la preparación delictiva que caracteriza a los "delitos de preparación". Pues bien, la sanción de la preparación delictiva no puede ser ni igual a la prevista para el tipo base ni a la del delito de tentativa. Esta valoración se caracteriza por su claridad expositiva, pero, lamentablemente, se desdibuja cuando las necesidades de prevención general orientan al legislador a establecer tipos penales que amenazan con consecuencias jurídicas desatinadas (me refiero a las penas excesivas que carac-

53 Mir Puig, S., Estado, Penal y delito, páginas 335-348. 
terizan a los "delitos de preparación"). Así, estimo que son decisiones inapropiadas, porque presuponen -en casos concretos- otorgar el mismo o similar nivel de injusto a las acciones de preparación frente a las tentativas o a la realización perfecta del tipo doloso previsto en la Parte Especial ${ }^{54}$. Esto, desde mi punto de vista, dificulta la valoración entre el injusto de preparación, tentativa y el injusto de la realización perfecta del tipo doloso mediante la exigencia de que las acciones preparatorias se agotan al efectuarse las conductas descritas en el respectivo tipo (tenencia, posesión, facilitación, fabricación, por ejemplo); y estas acciones no requieren una lesión, sino de una manifestación potencial para causar una lesión. Por tal motivo, podría imputársele al sujeto un proceso como conducta aunque carezca de dolo (una posesión de instrumentos de doble uso que se corresponda con los materiales u objetos descritos en un "delito de preparación”). Además, se podrían presentar supuestos donde se le haga a alguien responsable por acciones realizadas por otro ${ }^{55}$ (aplicar la sanción de estas normas por conductas de fabricación o creación de un programa informático o artefacto cuyo diseño y elaboración no es del sujeto incriminado) ${ }^{56}$.

Resulta también incorrecta la inclusión de estas normas en el $\mathrm{CP}$ cuando en ese mismo texto aparecen preceptos que protegen los mismos bienes jurídicos representados en los "delitos de preparación”. Ya hemos anotado que la protección aparece para un estadio no solo posterior a la preparación delictiva, sino previo (mediante la tentativa, por ejemplo). A mi juicio, mantener el castigo de la preparación delictiva que caracteriza a la figura que analizamos -sobrepasando "la excepción" que suponen los, ya bastante conocidos, "actos preparatorios punibles"- puede ser valorado como plausible siempre que se introduzcan estos instrumentos de anticipación ("delitos de preparación") para brindar una sobreprotección a bienes jurídi-

54 Mir Puig, S., Estado, pena y delito, página 349: “A mi juicio, -refiriéndose a la perfecta realización del tipo- el hecho doloso supone una oposición al bien jurídico más intensa e imputable al sujeto, lo cual, en parte, explica su mayor gravedad desde el punto de vista de los principios de protección de bienes jurídicopenales y de culpabilidad. El significado social de un comportamiento humano depende de si el daño que produce ha sido querido o no por su autor".

55 Véase también, Cerezo Mir, J., DP. PG., 2008, páginas 759-761.

56 En este aspecto, entra en juego el principio de culpabilidad, pues, como se sabe, nadie tiene por qué asumir la responsabilidad de la conducta ejecutada por otro. Empero, los arts. 248.2 b) y 270.6 sancionan tanto la posesión como la fabricación de objetos para delinquir. En esa línea, posiblemente "C" fabrique un programa para cometer una defraudación informática, pero el fabricador puede afectar mediante su acción a otro que no participó en ni la creación del programa ni en su posterior instalación; dado que "C" podría instalarlo en el ordenador de "B", compañero de trabajo. 
cos irrecuperables (vida humana, integridad sexual, estabilidad del Estado). Y ante conductas que ameriten tal grado de anticipación (aquellas que desde la preparación supongan un riesgo inequívoco; como la tenencia de armas nucléales. Esto encajaría en una "conducta preparatoria de tipo grave". Sin embargo, esta tesis no debe apreciarse como una especie de licencia para la redacción de penas desproporcionadas ${ }^{57}$. En esa línea, el criterio de "gravedad de la conducta preparatoria", es algo que se mide con arreglo a la proximidad de la realización perfecta del tipo doloso del respectivo delito fin y debe fundarse en la importancia del bien jurídico ${ }^{58}$ protegido y las consecuencias que se produzcan desde la preparación ${ }^{59}$. Esto dotaría a dicha figura de excepcionalidad, convirtiendo, desde mi parecer, a esta medida en razonable.

En la actualidad, es necesario realizar una interpretación restrictiva para la determinación del riesgo típicamente relevante (nivel alcanzado de preparación i idoneidad de los instrumentos $u$ objetos). Es imprescindible detectar la lesión efectiva al bien jurídico o, en su defecto, la puesta en peligro inminente desde la preparación, lo cual se consigue siempre que estas nociones estén dotadas de contenido. Es decir, cuando la conducta que encaja con el tipo objeto es indudablemente delictiva y requiere de un mínimo para causar una lesión a razón de la potencialidad de los instrumentos ${ }^{60}$.

57 Da razón de esto, Mir Puig, S., "Los límites del ius puniendi" en PEÑa CABRERA Freyre, R., et. al., (coords.), Libro homenaje al profesor Raúl Peña Cabrara, Lima, Ara, 2006, páginas 88-89.

58 Véase también, Paredes Castañón, J. M., La justificación de las leyes penales, páginas 248-250.

59 A este respecto, confróntese la tesis sostenida por GRECO, L., Lesione di un diritto anziché lesione di un bene giuridico?, (trad. Cozzolino), en Cavaliere, A., et. al., Politica criminale e cultura giuspenalistica. Scritti in onore di Sergio Moccia, Nápoles, 2017, páginas 332-336.

60 También sigue esta idea, Córdoba Roda, J., en Córdoba Roda J./García Arán, M., Comentarios al Código penal. Parte especial, Tomo 2, Madrid, Marcial Pons, 2004, páginas 1873-1874. Al referirse a la tenencia como delito permanente, afirma que: "Tal idoneidad o aptitud deben tener las cosas objeto de la tenencia o fabricación. La tenencia o fabricación de una materia que por sí sola no está en situación de realizar la fabricación, no dará lugar a la aplicación del presente tipo. Así, quien detenta un papel o una tinta que concretamente está destinada a la ejecución de una falsificación de papel moneda, pero que por sí sola no permite llevar a cabo la falsificación, no cumple el tipo del art. 400. Necesario resulta, pues, que la tenencia se extienda a una cosa o conjunto de cosas que por sí sean suficientes para ejecutar la falsificación". 


\section{CONCLUSIÓN}

La inclusión de los delitos de preparación engloba un asunto legislativo que, como vimos en estas páginas, exige razonabilidad, pues además de los problemas de proporcionalidad que denunciamos, se presentan también varias complicaciones. Me refiero a la incompatibilidad de algunos preceptos con los principios básicos del Derecho penal; sin ir más lejos: culpabilidad, legalidad, presunción de inocencia... Aunque la anterior disparidad no se presente en todos los "delitos de preparación", no podemos negar que la inclusión de estas figuras de adelantamiento no deja de estar lejos de una técnica legislativa plausible. Por eso, es necesario desprendernos de una mera potestad arbitraria o soberana, para acercarnos a medidas que se produzcan mediante criterios compatibles con los postulados de un Estado social y democrático de derecho. La sanción prevista para los delitos de preparación no depende del grado de afectación que estos causen a los bienes jurídicos protegidos; el legislador sanciona, como mostramos, de forma ilegítima la preparación delictiva, pues en no pocos casos equipara la preparación con la ejecución (del respectivo tipo base). Esta medida, desde todo punto de vista, se distancia de la función que el Estado asigna al Derecho penal.

Pues bien, proponer de manera general que las penas actualmente previstas para los "delitos de preparación" sean menores que las correspondientes a los supuestos de perfecta realización del tipo base o a la de la tentativa del respectivo delito fin, puede explicarse por diversas razones como aquí hemos intentado; esto es, por motivos de orden histórico, psicológico, legislativo y sociológico. Conjuntamente, podría justificarse en virtud de una combinada valoración entre la "gravedad de la preparación" y "las necesidades preventivas que afronta el legislador"; no obstante, estos motivos para disminuir las sanciones actualmente previstas en los "delitos de preparación" nos muestran que, en la actualidad, resultan insuficientes para el legislador, la realidad demuestra que no han sido valoradas, puesto que impera la discrecionalidad.

\section{BIBLIOGRAFÍA}

Aguado Correa, T., El principio de proporcionalidad en Derecho penal, Madrid, EDR, 1999.

AlCÁCER Guirao, R., “Tentativa consumación y anticipación de la protección penal: iter criminis y Derecho Penal económico" en SILVA 
Sánchez, J./Miró Llinares, F. (dirs.) La teoría del delito en la práctica penal económica, Madrid, La Ley, 2013, páginas 558-559.

Alonso De Escamilla, A./Mestre Delgado, E., en Lamarca Pérez, C., (coorda.), Delitos. La parte especial del Derecho penal, Madrid, Dikynson, 2015, páginas 707-712.

Alonso Rimo, A. ¿Impunidad general de los actos preparatorios? La expansión de los delitos de preparación, en InDret 4/2017, páginas 61-64.

Angioni, F., Concetto e funzioni del concetto di bene giuridico, Milán, Giuffrè, 1983.

Barber Burusco, S., «Del delito de "difusión" o "propaganda" terrorista a la desmesurada expansión de la punición de actos preparatorios», en CPC 2015 núm. 16.

Barber Burusco, S., Los actos preparatorios del delito, Granada, Comares, 2004, páginas 129-155.

Campo Moreno J.C., Comentarios a la reforma del Código penal en materia de terrorismo: La L.O. 2/2015, Valencia, Tirant Lo Blanch, 2015, páginas 61-63.

Campo Moreno, J.C., Los actos preparatorios punibles, Valencia, 2000.

Cano Paños, M. en Morillas Cueva, L. (dir.), Estudios sobre el Código penal reformado. Leyes Orgánicas 1/2015 y 2/2015, Madrid, Dikinson, 2015.

Cerezo Mir, J., Derecho penal. Parte general, Buenos Aires, Montevideo, BdF, 2008.

Colmenero Menéndez De Luarca, M., en Conde-Pumpido Ferreiro, C. (dir), Código penal comentado, 3. ${ }^{\mathrm{a}}$ ed., Tomo 1, 2012.

Córdoba Roda, J., en Córdoba Roda J./García Arán, M., Comentarios al Código penal. Parte especial, Tomo 2, Madrid, Marcial Pons, 2004.

CRUZ de Pablo, J.A., Derecho penal y nuevas tecnologías. Aspectos sustantivos, Madrid, Grupo difusión, 2006.

Cruz Palmera, Delitos instrumentales: Aspectos de Política legislativa, Buenos Aires, Montevideo, BdF, en presan.

ESPINOSA, P., «Modelos de conducta y toma de decisiones morales», en Clemente, M.,/EsPinosa, P., (coords.), La mente criminal, Madrid, Dikynson, 2001. 
FeIJoo SáNchez, B., Retribución y prevención general. Un estudio sobre la teoría de la pena y las funciones del Derecho Penal, Montevideo, Buenos Aires, Bdf, 2007.

Ferrini, C., Derecho Penal romano, Madrid, Marcial Pons, 2017.

Fiandaca, G./Musco, E., Diritto penale. Parte generale, 4. ${ }^{a}$ ed., Bolonia, Zanichelli, 2001.

Flores PRADA, Criminalidad informática: Aspectos sustantivos y procesales, Valencia, 2012.

Frister, H., Strafrecht, Allgemeiner Teil, 5. ${ }^{a}$ ed., Múnich, Beck C. H, 2011.

Fuentes Osorio, F., La preparación delictiva, Granada, Comares, 2007.

Gómez Martín, V., en Corcoy Bidasolo, M./Mir Puig, S.(dirs.), Comentarios al Código penal, Valencia, Tirant lo Blanch, 2015.

GRECO, L., "Lesione di un diritto anziché lesione di un bene giuridico?», (trad. Cozzolino), en Cavaliere, A., et. al., Politica criminale e cultura giuspenalistica. Scritti in onore di Sergio Moccia, Nápoles, 2017.

Greco, L., «Dolo sin voluntad», en RNFP, Vol. 13, No. 88, paginas 1619.

JaÉn Vallejo, M., Los principios superiores del Derecho penal, Madrid, Dikyson, 1999.

Jaén Vallejo, M./Perrino Pérez, A. en La reforma penal de 2015. Análisis de las principales reformas introducidas en el Código Penal por las Leyes Orgánicas 1 y 2 de 2015, de 30 de marzo, Madrid, Dikinson, 2015, páginas 195-196.

JAKoBs, G. en Estudios de Derecho penal, (trads. Peñaranda Ramos/ Suárez González/Cancio Meliá), Madrid, Civitas, 1997.

Lesch, H., El concepto de delito, (trad. Germignani), Madrid, Marcial Pons, 2016.

Lloria García, P., en Boix Reig, J. (dir.), Derecho penal. Parte especial, Vol. 3, Madrid, Iustel, 2012.

López Barja De Quiroga, J., Tratado de Derecho penal. Parte general, Cizur Menor (Navarra), Thomson Reuters Aranzadi ,2010.

Luzón Peña, D.M., Lecciones de Derecho Penal. Parte General, 3. a ed., Valencia, Tirant Lo Blanch, 2016. 
Manzanares Samaniego, J.L., Comentarios al Código Penal, Madrid, La Ley, 2016.

Mir Puig, S., Derecho penal. Parte general, 10. ${ }^{\text {a }}$ ed., Barcelona, Reppertor, 2015.

Mir Puig, S., "Los límites del ius puniendi" en Peña Cabrera Freyre, R., et. al., (coords.), Libro homenaje al profesor Raúl Peña Cabrara, Lima, Ara, 2006.

Mir Puig, S., Estado, pena y delito, Montevideo, Buenos Aires, BdF, 2006.

Miró Llinares, F., «La respuesta penal al ciberfraude. Especial atención a la responsabilidad de los muleros del phishing», en $R E C P C$, núm. 15 (2013).

Morillas Cueva, L. en Morillas Cueva, L., (coord.) Sistema de Derecho penal, 2. ${ }^{\text {a }}$ ed., Madrid, Dikinson, 2016.

Muñoz Conde, F., Derecho penal. Parte especial, 20. ${ }^{\text {a }}$ ed., (versión digital), Valencia, Tirant Lo Blanch, 2015.

Muñoz Conde, F./García ArÁn, M., Derecho penal. Parte general, 9. ${ }^{a}$ ed., Valencia, Tirant Lo Blanch, 2015.

NaucKe, W., Strafrecht. Eine Einführung, 8. a ed., Múnich, L.V.G, 1998.

Olmedo Cardenete, M., en Morillas Cueva, L. (dir.), Sistema de Derecho penal. Parte Especial, 2. ${ }^{\text {a }}$ ed., Madrid, Dikinson, 2016.

Orts Berenguer, E., en Vives Antón, T. (coord.), Derecho penal. Parte especial, 3. ${ }^{a}$ ed., Valencia, Tirant Lo Blanch, 1999.

Paredes Castañón, J., La justificación de las leyes penales, Valencia, Tirant Lo Blanch, 2013.

Pastor Muñoz, N. en Silva Sánchez, J., (dir.) y Pastor Muñoz, N. (coord.), El nuevo Código penal. Comentarios a la Reforma, Madrid, La Ley, 2012.

Queralt Jiménez, J., Derecho penal español. Parte especial, 6. a ed., Barcelona, Altelier, 2010.

Ramos VázQuez, J.A, en Quintero Olivares, G., (dir.), Comentario a la reforma penal de 2015, Cizur Menor (Navarra), Thomson Reuters Aranzadi, 2015.

Reyes Alvarado, Y., El delito de tentativa, Buenos Aires, Montevideo, BdF, 2016. 
Robles Planas, R., «La tiranía de la proporcionalidad», en García CAVero, P./Chinguela Rivera, A. (coodrs.), Derecho Penal y persona. Libro Homenaje al Prof. Dr. H.C. Mult. Jesús María Silva Sánchez, Lima, Ideas, 2019.

Robles Planas, R., «Introducción a la edición española. Dogmática de los límites al Derecho penal», en Hirsch/SEELMAN/WoHLERs, Limites al Derecho penal. Principios operativos en la fundamentación del castigo, Barcelona, Atelier, 2012.

Rodríguez De Santiago, J. M., La ponderación de bienes e intereses en el Derecho administrativo, Madrid, Estudios Jurídicos, 2000.

Rodríguez Devesa, J., Derecho penal español. Parte especial, 14. a ed., Madrid, Dikynson, 1991.

Roxin, C. "El fundamento del castigo de la tentativa idónea e inidónea” (trad. Queralt), en Silva Sánchez, et. al., (coords.), Estudios de Derecho Penal. Homenaje al profesor Santiago MIR PUIG, Buenos Aires, Montevideo, Bdf, 2017.

Roxin, C./ Greco, L., Strafrecht, Allgemeiner Teil, Tomo I, 5. ${ }^{\text {ed., Mú- }}$ nich, C.H. Beck, 2020.

Sanz Mulas, N., Política Criminal, Salamanca, Legis Jurídica, 2016.

Serrano Gómez, A./Serrano Maíllo, A. en Serrano Gómez, A., et. al., Curso de Derecho Penal. Parte Especial, 4. ${ }^{\text {a }}$ ed. Madrid, 2017.

Silva Sánchez, J.M., en Silva Sánchez, J.M., (dir.)/Ragués I Vaallès (coodr.), Lecciones de Derecho penal, 5. ${ }^{\mathrm{a}}$ ed., Barcelona, Atelier, 2018.

Zugaldía Espinar, M., Fundamentos de Derecho penal, 3. a ed., Valencia, Tirant Lo Blanch, 1993. 
